IMAGINARIOS URBANOS DE VALPARAÍSO EN LA CIENCIA FICCIÓN CHILENA RECIENTE : TRANSITAR Y HABITAR LA CIUDAD

\title{
Urban Imaginaries of Valparaiso in Recent Chilean Science Fiction: Traveling and Inhabiting the City
}

\author{
ESTEBAN BORIS VERA CAMPILLAY \\ UNIVERSIDAD DE CHILE (Chile) \\ estebanbvera@gmail.com
}

\begin{abstract}
Resumen: el siguiente artículo propone la idea de formación de imaginarios urbanos a partir de la ciencia ficción chilena reciente que versa sobre la ciudad de Valparaíso. Estos imaginarios serán constituidos por medio del habitar y transitar los diversos espacios urbanos que la componen. Finalmente, se establecen las proyecciones hacia la ciencia ficción chilena reciente y el rol que juega la ciudad dentro de la literatura del género en tiempos actuales $\mathrm{y}$, de esta forma, situar a la ciencia ficción dentro de la discusión de la ciudad de Valparaíso en la literatura.

Palabras clave: ciencia ficción chilena, Valparaíso, imaginario urbano, transitar, habitar
\end{abstract}

Abstract: The following article proposes the idea of the formation of urban imaginaries from the recent Chilean science fiction that deals with the city of Valparaíso. These imaginaries will be constituted by inhabiting and moving through the various urban spaces that make it up. Finally, the projections towards recent Chilean science fiction and the role that the city plays within the literature of the genre in current times are established, and in this way, place science fiction within the discussion of the city of Valparaíso in literature.

Keywords: Chilean Science Fiction, Valparaíso, Urban Imaginary, Traveling, Inhabiting 


\section{El caso de Valparaíso en las representaciones simbólicas e imaginarios de las} ciudades en la ciencia ficción

Para dar inicio al presente estudio, conviene establecer las rutas de lecturas y propuestas para plantear el tema en cuestión. Para ello, es preciso situarlo en el tipo de ciencia ficción latinoamericana, la cual evidencia una identidad cultural disruptiva; donde son representados temas locales para dar cuenta de los problemas de cada espacio, junto con denunciar las atrocidades causadas en su sociedad por los cambios histórico-políticos que ha tenido (Ferreira, 2019: 666). En este sentido, cabe la posibilidad de ser una herramienta que permita comprender la desigualdad del proyecto modernizador latinoamericano, además de traer nuevas historias y nuevos contextos a la discusión y a la ficción que escapan del hard y sean la puerta de inicio para analizar las problemáticas de las identidades del sur de América (677-678).

Por este motivo, y con el fin de direccionar la investigación, se debe entender la concepción de la ciudad de Valparaíso como parte de las urbes que han gestado los espacios y la producción literaria latinoamericana (Solar, 1964), lo cual da inicio a la vasta tradición artística de estas ciudades con su entorno además de la narrativa concebida desde ellas. De esta manera, la prospección histórico literaria de Valparaíso $\left(\right.$ Solar, 2001) ${ }^{1}$ resulta primordial para las literaturas regionales de Chile.

En este sentido, bajo las ideas de Aragón (2014), Valparaíso será el significante que envolverá a sus habitantes, donde la apertura de sus símbolos será en "palabra, espacio y lugar" (9), y a su vez, estos serán metafóricos e icónicos (15), es decir que, a partir del contexto espacio-temporal, esta urbe funciona, representa y comunica constantemente. Parte importante de esta fuerza significativa la tendrán sus habitantes, puesto que irán representando cada significación dentro del significante-ciudad a medida que estos la habitan y transitan, como una especie de análisis de la interpretación de sus huellas (Margulis, 2002: 516). Además, la urbe crea un lugar donde "los significados pasan y los significantes quedan" (Barthes, 1990: 262), lo cual permite reinterpretar los espacios físicos, que van interponiéndose a medida que la lectura de las novelas atraviesa sus rincones.

\footnotetext{
${ }^{1}$ Si bien Claudio Solar es uno de los exponentes más destacados por su arduo trabajo documentado, también se sugiere el ensayo enfocado más en la lírica que realiza Novoa, Marcelo (1996), Álbum de Flora y Fauna. Valparaíso, Ediciones del Gobierno Regional de Valparaíso, quien además es parte importante de la formación de la literatura de ciencia ficción en la región con la fundación y liderazgo de la Editorial Puerto de Escape, especializada en ciencia ficción y fantasía.
} 
Bajo esta perspectiva, la misma idea de concebir la ciudad desde su concepción simbólica ${ }^{2}$ e imaginaria da como resultado una nueva forma de su significación e interpretación en un determinado contexto y que, para este caso, pretende demostrar como los imaginarios urbanos de la ciudad de Valparaíso en la ciencia ficción chilena reciente se constituyen a partir del sujeto que la habita y transita en sus múltiples espacios interrelacionados y de qué manera la dinámica entre ambos aspectos permite la apertura de nuevas formas de visualizar a esta ciudad en la literatura.

Para ejemplificar lo propuesto, el corpus de obras narrativas revisadas tiene una extensión de publicaciones que cubren una década: Fractales (2006) de Sergio Meier; Barcelona de Néstor Flores Fica (2006); Valpore (2015), publicada el 2009, de Cristóbal Gaete; Próximo Destino y otros relatos de XS 200, de Cristián Briceño (2014); y por último, Evento Z. Zombies en Valparaíso, de Martín Muñoz Kaiser (2014). En conjunto, estas obras presentarán los imaginarios que se forman en la ciudad de Valparaíso. Estamos, pues, frente a narrativas que permiten entender la importancia que está alcanzando la ciencia ficción chilena y el rol de la ciudad de Valparaíso como recepción imaginaria y simbólica en la interpretación de los fenómenos literarios.

Para este propósito, conviene delimitar que la idea de abrir el espacio urbano porteño hacia el objeto de estudio es también una propuesta de enfatizar en las ya mencionadas literaturas regionales, donde Adolfo de Nordenflycht (2009) afirmaba que han "potenciado un resurgido interés por las manifestaciones de identidades locales y fragmentadas que se reclaman en el despliegue de comunidades que antes fueran avasalladas por el proyecto modernizador y sus secuelas" (155). Esta noción de identidad local y fragmentada se establece directamente con Valparaíso, una ciudad que tuvo su apogeo durante gran parte del siglo decimonónico hasta la construcción del Canal de Panamá. La ciudad así, y volviendo a los estudios de Nordenflytch (2011), presenta cuadros expresionistas literariamente hablando:

una arquitectura distorsionada siempre a punto de colapsar, de edificios de fachadas asimétricas, tabernas oscuras, casas colgando de los cerros construidas conforme al temperamento individual de sus habitantes, escaleras inverosímiles, almacenes portuarios abandonados, depósitos,

\footnotetext{
${ }^{2}$ Entendida según lo presentado por Durand, Gilbert (1968). La imaginación simbólica. Buenos Aires, Amorrortu, quien propone que la representación de una idea o significado resulta imposible de presentar de manera directa, puesto que el significado aparecerá después de haber problematizado al significante, al punto de adquirir una fuerza semántica que se expande con el tiempo, es decir, un pensamiento simbólico.
} 
construcciones semiderruidas, calles que se pierden oblicuamente, perspectivas falseadas, luces y sombras angulosas. (125)

En esta situación, Valparaíso tendrá bastante que decir luego de su abandono del centro. Así mismo, ha sabido sobrevivir, pero también autodefinirse a través del paso del tiempo y de los imaginarios que han ido estableciéndose. Con el transcurso del tiempo, la ciudad se vio arrojada a la periferia, no tan solo desde su dimensión económico-social sino también simbólica. Bajo este contexto, ¿cómo es que en un caso así, a más de un siglo de ese evento, haya sido posible que Valparaíso resurja como una ciudad donde la ciencia ficción asiente bases y potencie su (re)interpretación desde su dimensión simbólica e imaginaria? ¿Qué papel juega el sujeto que la habita y transita en estas narrativas?

Antes de seguir, conviene establecer el punto de partida contextual del objeto a analizar. Para este orden de ideas, Novoa (2006) destaca el carácter pionero del género de lo que él mismo denominó la ciencia ficción criolla, con obras como ;Una visión del porvenir! (1875), El espejo del mundo en el año 1975 (1875), de Benjamín Tallman; Ocios Filosóficos y Poéticos en la Quinta de las delicias (1829) de Juan Egaña; o Don Guillermo, de Lastarria (1842); Los anteojos de Satánas (1871) de Liborio Brieba, hasta Desde Júpiter, de David Miralles (1878), que ya comienzan a situar el espacio de Valparaíso en lo que vendrían a realizarse a mediados del siglo XX en Chile. ${ }^{3}$ Para este siguiente momento, Areco (2015) identificaba diversos períodos en que se fue desarrollando el género. De esta manera, establece al menos seis lapsos de gestación: el de "Fundación" (116), "Preludio" (118), "La edad de oro" (120), "El decaimiento y repuntar" (122) desde la Dictadura de Pinochet en Chile, a lo que vendrá una "Recuperación" (125), y finalmente, una "Nueva Edad de oro" (128). Frente a estas décadas extensas de ciencia ficción en Chile, resulta conveniente extraer de aquel prólogo que Alfonso Calderón daba en la Antología de cuentos chilenos de ciencia ficción y fantasia, de Miguel Rojas Murphy (1988), el hecho de que haya escritores chilenos de ciencia ficción, quienes denotan fallas, ansiedades y dudas que asaltan al ser humano, como una manera de decirnos de dónde somos y en qué estamos.

Lo anterior direcciona la escritura de ciencia ficción desde su poética sociológica para lograr un nexo hacia la ciudad. En este sentido, Darko Suvin, en la traducción de Roy Alfaro (2020), planteaba el extrańamiento cognitivo, donde el ambiente empírico del autor se desliza hacia una novedad rara planteada, es decir, un "novum" (225). Por consiguiente, la ciencia ficción "ve

\footnotetext{
${ }^{3}$ Resulta interesante mencionar una novela previa. Thimor (1932), de Manuel Astica Fuentes, es una obra que sitúa a Valparaíso como espacio del imaginario de la novela como inicio de exploración de un axis mundi llamado Thimor.
} 
las normas de cualquier época, incluida enfáticamente la suya propia, como única, transformable y, por ende, sujeta a una mirada cognitiva" (227). Es más, Suvin marca la diferenciación netamente cientificista o de anticipación tecnológica con el cual se ha categorizado a la ciencia ficción cuando afirma que, dentro de ella "Esta no pregunta por El Hombre o El Mundo, sino ¿cuál hombre?, ¿en qué clase de mundo?, ¿y por qué tal hombre en tal clase de mundo?" (2020: 227).

Frente a todo esto, y entre una serie de experimentalismos, rupturas y transgresiones, Marcelo Novoa afirmaba que la ciencia ficción se compone mediante mezclas con la literatura general, "libre de pasados culturales agobiantes o luchas de mercadeo, intenta atemperar regionalismos y claves locales con la vitalidad y originalidad visionarias" (2017). Es esta visión de la ciencia ficción emergente en Chile, y más específicamente en la ciudad de Valparaíso, lo que llevará a considerar la lectura de obras literarias que sirvan de base para el análisis de un fenómeno propio que las nuevas directrices del género está consolidando.

\section{Constitución y destrucción en el imaginario de Valparaíso}

En Próximo Destino y otros relatos de XS 200 (2014), se relata la creación de un sistema interplanetario en un tiempo lejano, donde la sociedad vive un futuro incierto, existencial y apocalíptico. Dentro de este contexto, Cámara 7 se presenta como un relato que visualiza un retromundo llamado Tierra y en particular sobre una ciudad llamada Valparaíso. En este sentido, el cuento opera bajo la visión de mundo posible creado a partir de una sociedad situada en un futuro lejano. De acuerdo a la obra, Gabriel, protagonista de la historia, ensueña con dicho lugar:

—Anoche casi no pude dormir sońando con esa ciudad que se llamaba Valparaíso y... eso que era el... Océano Pacífico.

—Pero Gabriel, si el profesor ya nos ha repetido hasta el cansancio que eso es solo ficción. Si hasta el nombre es demasiado idílico.

—Eso lo dices tú, que no crees en nada. No vengas a decir, acaso que le crees al profesor...

[...] Gabriel continuó leyendo el libro en el cual se apreciaban ilustraciones de una ciudad que colgaba de los cerros. Sońaba con poder encontrar alguna ciudad como esa en algún lugar de aquel planeta, aunque fuese casi una tarea de arqueología en medio de tantos edificios enormes. (20)

Valparaíso, como símbolo, construye una percepción de un lugar ameno, esto es, un topoi urbano que se desea, idea que va calando hondo en la mente de los 
personajes. Si se tienen en cuenta estas significaciones que van más allá de los significantes de la ciudad, surgen representaciones y se constituyen los imaginarios sociales. Cornelius Castoriadis demostró en su obra La institución imaginaria de la sociedad (2007) cómo surgen los imaginarios y cuál es su sustento socio-teórico. De esta forma, se entiende a la institución, como parte esencial de la ciudad, la cual actúa por excelencia en el plano de lo simbólico, al responder a las "necesidades vitales" (185), pero dado que una sociedad no es solo esto, se buscan también satisfacer las "necesidades reales", es decir, las otras distintas a las biológicas. Con respecto a lo simbólico, cada institución opera con sus propios significantes y significados, lo que muchas veces produce un simbolismo "vaciado de sentido" (190), vale decir, cuando se separa de la ficción y es independiente a esta.

$\mathrm{Al}$ considerar lo anterior, y retomar el relato, el deseo del protagonista se vuelve realidad cuando logran tripular la misión que los llevaría hacia su "próximo destino":

La cantidad de luces podía iluminar el universo en su totalidad. La nave descendía, envuelta en llamas. Pudieron divisar un enorme macizo rocoso; eran montańas enormes cubiertas de nieve que se extendían desde latitudes insospechadas. Se acercaron a una ciudad completamente iluminada; las luces caían desde los cerros y parecían desembocar, como un río, en el mar. Continuaban el descenso hacia un mar tranquilo y pacífico como el silencio que los rodeaba. La nave cayó sobre el agua, donde el fuego se hizo humo que luego desapareció rápidamente. Saltaron de la nave al agua y nadaron hasta la orilla.

—Esto es increíble. Esta metrópolis parece muy antigua.

—Esta es la descripción de una... ¿cómo era la palabra? ¡Ciudad! Sí, de una "ciudad" de las que hablaba Gabriel. (74)

Llama la atención que, tras la mirada de estos extranjeros, estos otros, y su alta tecnología a eones de distancia de este sector del universo, reconocían el espacio al que llegaron como una metrópolis antigua, como una ciudad. En este sentido, el deseo de ver una ciudad y proyectarse en ella hacia la visión de habitarla era lo que predomina en los personajes de la historia. Valparaíso aparece entonces como una ciudad prospectiva (Moreno, 2011); desde su lejanía, tanto como discurso y como relato, se realiza un acto de habla que forja una realidad inminente.

Estas visiones se contextualizan con los argumentos de las ciudades futuras que mencionaba Lawrence (2020), donde el posthumanismo, así como las bases políticas y económicas para la constitución de la ciudad, permiten una extrapolación distópica de las leyes alternas y limítrofes entre las proyecciones políticas modernas y posmodernas. Por tanto, las visiones postcapitalistas de la imaginación en futuros ya escritos o proyectados en nuestra realidad se reproducen con las luchas entre: una utopía propuesta para desafiar el período del Antropoceno en el que actualmente se arroja la sociedad humana, contra una distopía capitalista inminente (314-322).

Por otro lado, frente a la constitución de la ciudad distópica y sus luchas para desafiar el propio escenario de autodestrucción del ser humano en una 
sociedad de consumo y de desechos, existe el imaginario de las calamidades que han forjado a la ciudad-puerto, bajo la perspectiva de construcción y destrucción. Esta hibridez, propuesta por Candia y Guerra (2018), permiten mostrar su lado oscuro (99). De este modo, logran establecer una perspectiva histórico-literaria de Valparaíso interpretado desde tres perspectivas: "La ciudad del fuego" (100); "Valparaíso bajo ataque" (103); y por último, “Tierra rota" (106). Esta triada propone entender que las catástrofes configuran el imaginario urbano de la ciudad y, a su vez, permiten comprender la visualización de una urbe que se representa desde la visión de una ciudad en constante acto de estar arruinándose desde el punto de vista geográfico-simbólico.

En este contexto, Valparaíso se logra representar bajo una inminente destrucción. Esto se puede apreciar en el relato de Sergio Meier, Fractales (2006), donde la narración sitúa el espacio de la ciudad como el escondite de una antigua fórmula para hacer un multifractal (14), o "fractal maestro" (16). Un objeto que permita ver las dimensiones del multiverso. Lo que nos da a conocer tal información serán las acciones y labor del profesor Salvo, quien conversa con el protagonista, un sujeto sin nombre, sin una identificación excepto la física y de ser un extranjero en la metrópolis. En este contexto, dicho protagonista recorre las calles de una ciudad en el futuro donde: "las plazas, con sus fuentes de estilo francés, con sus estatuas cubiertas de orín y graffitis fosforescentes, albergaban ejércitos de vendedores ambulantes, exhibiendo toda clase de ordenadores usados y equipos de sustentación vital, en su mayoría de principios del siglo XXI" (4).

Llama la atención la particularidad del Valparaíso descrito, donde sus puntos de conexión con el imaginario y simbolismo de la ciudad serán las marginalidades de su composición, a saber, la decadencia de una ciudad en ruinas trasciende hasta el punto de recrear un imaginario para recrear el mundo. Por otro lado, el imaginario de una ciudad abandonada, en decadencia y fragmentada, donde se presenta la comprensión del universo y sus leyes avanzadas, donde los primeros Dioses luchaban cíclicamente por el dominio del universo. Confinados en sus derrotas, fueron desterrados a exilios espaciotemporios y que ahora los físicos habían comprobado plenamente, junto con la existencia de dichos "pliegues dimensionales y de los múltiples universos que podían albergar todo cuanto la mente fuera capaz de imaginar... Desde los más excelsos paraísos hasta los más atroces infiernos" (Meier, 2006: 5).

Con respecto al objeto que el protagonista tenía, este representa la conexión de la nada y el todo, es decir, un fragmento de algo, ${ }^{4}$ que sirve para contactar con el todo del universo. Con una verdad esencial. El papel se invierte en la narración, se concibe este pedazo como la esencia de una ciudad llamada Valparaíso, un fragmento que el protagonista mantiene en sus manos y al cual se le describe de la siguiente forma: "Los fractales eran la clave del orden en el aparente caos, las semillas de la estructura del cosmos [...] Donde otros habían fallado, el programa 'Valparaíso' (o mejor dicho 'Valinferno') había tenido éxito, despertando al verdadero monstruo de Mandelbrot (Meier, 2006: 14).

\footnotetext{
${ }^{4}$ Resulta interesantísimo el concepto de fractal, según la ciencia, para entender este relato.
} 
Visto bajo esta perspectiva, Valparaíso viene a ser una ciudad prospectiva en donde la misión más importante de una civilización se da a conocer $y$, al mismo tiempo, pasa tan desapercibida como aquel vendedor ambulante de alguna de sus calles, ferias, o inclusive, de alguna de sus murallas rayadas. Es esta constitución de sus símbolos que "edifica sobre la ruina de los edificios simbólicos precedentes y utiliza sus materiales" (Castoriadis, 2007: 194). En este sentido, lo relativo a una ciudad en decadencia se transmite hacia las novelas, un espacio hostil para sus habitantes, donde ese fractal ya se ha abierto dentro del imaginario de la urbe. Esta idea de construir a partir de lo que se destruye determina la constitución de imaginarios en Valparaíso, el cual retoma toda crisis y todo imaginario que se va resignificando.

\section{Valparaíso como imaginario urbano de la ciencia ficción chilena reciente}

Para entender la constitución del imaginario de la ciudad de Valparaíso, resulta necesario situarla en lo que Cisternas (2011) denomina Metrópolis: como una ciudad matriz a otras, que distanciará el abismo entre lo sagrado y lo secular (69). En este espacio, resulta difícil integrar elementos culturales dispares. El individualismo será un elemento negativo dado que termina por romper lazos sociales. Sin crear un nuevo orden, el nuevo desorden es el caos. La lucha de clases es una fuerza núcleo en todo ámbito de progreso y, por tanto, lo será también la lucha de poder. En este sentido, el sujeto urbano-narrador/enunciador de la experiencia urbana pasa a ser también el sujeto estético siempre y cuando su espacio-tiempo (o cronotopo) se dé como experiencia límite, es decir, mientras habite y transite por la metrópolis. Esta idea de fragmentar el habitar hace que las ciudades no tengan un orden regular, por lo que se evidencian en los mismos espacios, la decadencia y degradación capitalista de vivir, a saber, consumir en la ciudad: todas estas son características de la ciudad de Valparaíso. Además, el dominio del barrio se reemplaza por el condominio, la propiedad patrimonial y el arriendo, el espacio se privatiza, donde "todas las degradaciones posibles del concepto de habitar como un acto trascendente [...] ya se han consumado" (71). En este lugar, el sujeto que la habita y transita anhela una vida anterior a la metropolitana, previo a la ciudad mundial, dado que esta adocena y normaliza la identidad, por esto buscará construir su identidad en los sistemas tribales, alternativos, para dar un sentido al habitar ciudadano. La simbiosis será el circuito comunicativo estético con el contexto urbano (89), puesto que se busca la complicidad del lector con la narración de la ciudad, al exigir tener un lenguaje del mapa mental común, hacia un ethos crítico: el lector debe ser alguien que haya experimentado la crisis de habitar en la ciudad (89).

Por otro lado, los símbolos citadinos universales de Valparaíso serán su carga distópica y utópica que ha sido un eje transversal en el discurso literario. La norma es moldeada hacia una representación y caracterización de la ciudadpuerto vista desde un punto de vista en particular que muchas veces se confunde con la deducción de otra ciudad montada sobre la vieja. La imagen dialéctica que analizaba Walter Benjamin sobre la urbe (1982) es una confirmación de una 
imagen de sueño que ha permanecido constantemente y ha excluido a la memoria de la constitución de la ciudad.

Para el caso de las narrativas urbanas, las representaciones surgen a partir de tropos narrativos particulares, lo cual reafirma el cliché de la inestabilidad de una ciudad dividida contra sí misma en la constante búsqueda de pureza y homogeneidad en cualquier parte de las fuerzas que accionan en ella pero, a su vez, entrega algunas posibilidades donde "the divided city breeds a rebellious offspring that restores the urban experience to all its messy glory" (Gomel, 2018: 142). De esta manera, la ciencia ficción traduce la topografía en topología donde se tratan diferentes lugares en diferentes espacios y en cada uno de ellos hay leyes físicas distintas, las cuales crean espacios monstruosos sociales físicamente fragmentados, separados del resto (Gomel, 2018: 143), lo cual provoca una separación no solo de lugares, sino de espacios y realidades ontológicas. Las siguientes obras ejemplificarán este asunto.

En Evento Z. Zombies en Valparáiso (2014) de Martín Muñoz, la idea de un Valparaíso escatológico no deja de ser más interesante que un Valparaíso apocalíptico. En específico, donde se narre el fin del mundo para el humano. ${ }^{6}$ Resulta atractiva la posibilidad de que el fin del mundo llegue a Valparaíso a través de este tipo de criatura, un zombie, ${ }^{7}$ de un Otro desbordante, que no escatima en esfuerzos por entender su espacio, sino que lo destruye hasta la aniquilación total. El monstruo prospectivo será el que termine dominando la ciudad prospectiva hasta aniquilarla. De esta forma, la transformación de la Metrópolis en Necrópolis antecede la degradación absoluta, donde el saqueo forma un acto de salvación de parte de todos los grupos sociales en especial, el político, quienes terminan por apartarse de esta destrucción.

Si se vuelve al análisis en sí, la narración empieza con Uluf Linström, un ciudadano caucásico, quien cae muerto en seguida de haber desembarcado desde un transatlántico en Valparaíso. La narración revela un mundo donde se describe la ciudad:

El puerto principal de Chile contaba con un par de playas populares y un terminal de cruceros donde embarcaban anualmente unas cien mil personas de diferentes nacionalidades, que acudían a visitar la particular

\footnotetext{
${ }^{5}$ Traducción: "la ciudad dividida engendra una descendencia rebelde que devuelve la experiencia urbana a toda su desordenada gloria”, una cita que se aplica muy bien a Valparaíso en la literatura de ciencia ficción.

${ }^{6}$ En este contexto, El último hombre (1826) de Grainville predice una catástrofe futura que ocurriría en el siglo XXI: "[...] se trata de una plaga que arrasa con la especie humana, dejando escasos supervivientes en una Tierra desolada" (Vega, 2006: 85). En este sentido la novela de Muñoz viene a ser lo que Camille Flammarion, en El fin del mundo (1893), ya había postulado. Un final causado implosivamente, un colapso social desde la ciudad hacia adentro.

${ }^{7}$ Dicho esto, y fuera de las series masivas por internet, tales como The walking dead (2010-), o películas como World War $Z$ (2013), e inclusive videojuegos como The last of $U_{s}$ (2013) o The last of Us 2 (2020), tratan esta temática, al dar por hecho una especie de remixización, de un pastiche, donde se logra germinar la concreción literaria de una ciudad prospectiva infestada de zombies.
} 
ciudad, donde aún transitaban viejos troles y funcionaban varios funiculares, que iban desde el centro hacia el corazón de los barrios encaramados y escondidos entre los cerros. Jamás fundada, Valparaíso nació como un pequeño puerto en torno al cual se construyeron sus distintas casas y edificios, generando un paisaje de pasadizos, escaleras y callejones estrechos en donde se mezclaron estilos arquitectónicos sin ninguna lógica o escrúpulo. Un proceso caótico y desordenado, carente de planificación urbana, que dio como resultado un mosaico único y decadente que atraía a los visitantes, a los bohemios y a los poetas. (Muñoz, 2014: 20)

Este invasor, este extranjero, en un simbolismo de la decadencia posmoderna, dado su fracaso como esposo, ciudadano y turista, termina infectado de un extraño virus que muta en él hasta convertirlo en un Otro que se propone consumirlos a todos. ${ }^{8}$ En este espacio, se relata lo ocurrido con Javier, uno de los protagonistas, proveniente de una familia tradicional, obrera del trabajo arduo, en la que "su papá era como un autómata que manejaba en piloto automático hacia el colegio (Muñoz, 2014: 21). Javier, se preparaba con su amigo Weipin, con quien, dentro de sus juegos de supervivientes, habían visualizado un caso así. Por su parte, los adultos no tendrán mucho que contar en esta historia, puesto que son aniquilados por ellos mismos o por estas criaturas.

En este sentido, la ciudad se transforma, muta; y si el espacio lo hace, también lo harán sus habitantes. Los espacios de interacción se transforman en espacios de hostilidad, de modo que: "Los zombis representan un excelente símbolo de la masa y de las imposiciones sociales del Otro colectivo contra el Yo individual" (Moreno, 2011: 490). Pronto, Valparaíso pasa a desarrollar un nuevo vínculo: la de la ciudad de los vivos con la ciudad de los muertos, en un eje mítico-religioso. Con respecto al modo en que este imaginario de ciudad recibe la infestasión, no resulta alentador:

Los más paranoicos predicaban conspiraciones de las farmacéuticas para ganar más dinero vendiendo vacunas para atacar enfermedades diseñadas en sus propios laboratorios; otros hablaban de un virus que desaparecía a las dos semanas de ser inculcado, si uno resistía los síntomas de la enfermedad, y que provocaban muertes solo entre bebés, ancianos y enfermos. Ahora bien, todas estas hipótesis provenían de fuentes no oficiales, todas páginas web de carácter amarillistas y poco fiables, pero muy entretenidas. (Muñoz, 2014: 23) ${ }^{9}$

\footnotetext{
${ }^{8}$ Resulta sumamente potente esta presentación del personaje otro, este extranjero que trajo su virus mortal. En este sentido, es imposible no compararlo con la situación actual vivida en Valparaíso y también a lo largo de las metrópolis del mundo durante el año 2020, donde el COVID-19 ha sido interpretado desde los imaginarios de la ciencia ficción.

${ }^{9}$ Es tentador realizar una comparación a la realidad contingente del mundo, y cómo se maneja la información del COVID-19 con el fragmento citado, son contextos imantados de similitud.
} 
Este mundo patas para arriba (39) resulta ser el desgrane en Valparaíso (52). La imagen de la ciudad demuestra una realidad que poco a poco se va a transformar en una verdad:

Los tres compañeros de trabajo estaban en el nacimiento de la Avenida Argentina, una recta de unos veinticinco metros de ancho que va desde las faldas del Cerro O’Higgins hasta la zona portuaria, con un enorme bandejón central sobre el cual los miércoles y los sábados se instalaba la feria de frutas y verduras a la cual asistía la mayor parte de los habitantes de la urbe. Los otrora pasillos de lona y vegetales eran ahora un laberinto donde los agudos dientes de los dementes acechaban a quien se atreviese a entrar. (Muñoz, 2014: 65)

La imagen de una ciudad repleta de hambrientos no es más que el símbolo prospectivo de un imaginario propio de la ciudad de Valparaíso. Esta será la visión en ruinas que se sigue arruinando (77-79). Sin embargo, la sensación anárquica de libertad, en una ciudad destruida (80), permite hacer un recorrido por Valparaíso desde las estructuras sociales, puesto que el ascenso y descenso social de los grupos privilegiados se constituye (Muñoz, 2014: 122-123).

Retomamos el punto de partida para subrayar que esta pérdida de humanidad en la sociedad permite una situación única; gracias a la destrucción de los habitantes de la ciudad, la urbe toma un protagonismo como personaje al rechazar todo rasgo de existencia anterior, además que permite la ventaja de conocer sus restos de una manera distinta (156). En este sentido, además de que se muestre a Valparaíso como Mausoleo (159). Se logra entender el propósito de que los nińos sobrevivieran: son las semillas de un nuevo mundo (183), para un mundo viejo que será destruido por el fuego de cientos de bombas nucleares, pero irónicamente permite dar a conocer un hecho innegable del imaginario del Valparaíso: al final, los ricos y poderosos se salvan (Muñoz, 2014: 188).

No obstante, mostrar extensivamente la serie de aniquilaciones de cada uno de los personajes que van formando parte del relato da cuenta de una destrucción progresiva del Yo, no solo desde el Otro, sino desde el mismo Yo. Es en este punto que, bajo la perspectiva de Lucía Guerra (2014), las cargas connotativas de centro, ángulo y periferia son una gran estructura de poder que se basa en el orden y la circulación social y política, la cual permite que en las zonas de la ciudad se desenvuelvan "tramas ideológicas" potentes. Ahora bien, la presencia (y ausencia) de ciertos personajes permiten la apertura de simultaneidades raciales, sociales, y genéricas que se posicionan en el mismo nivel que los grupos hegemónicos. La ciudad se transforma en un espacio heterogéneo por más homogeneizador que sean sus símbolos oficiales.

Sin embargo, la mera circulación peatonal y física por la ciudad no es suficiente para abordar el problema en sí, se necesita habitar y vivir la ciudad, de esta forma, la presencia de la subjetividad será pues un lugar de encuentro con el otro, por tanto, la delimitación estética será la forma de trabajar el espacio de la ciudad, dado que estas permitieron identificar el origen de la ciudad desde su 
símbolo y otros ámbitos. Este intento de elaborar un discurso para verbalizar la ciudad es el proceso de elaborar un imaginario de la misma, en tanto proyecta lo connotativo hacia los planos subjetivos de la perspectiva personal. En este punto, Lucía Guerra (2014) afirma que "un análisis de los imaginarios urbanos debe tomar en cuenta las cartografías significantes insertas en diversas interrelaciones de poder en un espacio y tiempo específicos" (27). En este sentido, el hecho de determinar en un período de tiempo que abarca desde mediados de la década pasada al presente resulta fundamental para lograr comprender la mutación de la ciudad de Valparaíso en la literatura.

Es necesario precisar lo anterior y señalar que la mayoría de las ciudades de la ciencia ficción suelen presentarse a través de espacios distópicos, los cuales son simbolizados desde las hegemonías establecidas hacia las marginalidades encontradas en ella misma y desde su periferia. Aparecen, entonces, cuando la ficción prospectiva presenta un mundo abominable con problemas propios a los tiempos posmodernos. En estos espacios, sus personajes se confunden con las masas (un everyman) habitando en un mundo donde la relación entre poder y verdad ya no son posibles (Villanueva, 2018: 509). Es la idea cronotópica de transgredir el modelo espacial establecido en la narración mediante otro espacio que está de manera implícita en el primero, es decir, la ciudad se transgrede, destruye y construye a sí misma.

En Valpore (2015) de Cristóbal Gaete, Valparaíso se presenta como un espacio donde los imaginarios comunes entran en conflicto con los disidentes de la ciudad; punks, mendigos, borrachos, decenas de nińos y otros marginados, quienes serán los sujetos de relieve de esta historia. Sus protagonistas habitan en una casa ocupa de Valparaíso, entre esta y Valpore: un sector escondido dentro de los suburbios de la ciudad, en representación del descontrol y de sujetos marginalizados dentro del imaginario de Valparaíso que acuden a vivir a este espacio. Más aún, es una ciudadela, una fortaleza hecha creada y erigida en lo alto de la periferia de sus cerros como los restos de la ciudad posmoderna del Puerto; aquí es donde los niños viven en jaurías infantiles cazando hombres, mujeres, niños y niñas sin distinción, hogar de nuestros protagonistas. El espacio descrito será un locus eremus, es decir, un lugar de destierro, no deseado, un yermo donde se presentarán escenas de violencia psico-física y simbólica que, poco a poco, comenzará a desplazarse hacia Valparaíso.

La marginalidad mencionada no solo se le atribuye al espacio físico del último cerro de la ciudad, sino también a quienes transitan por los espacios centrales de la urbe, por tanto, socava la idea de un patrimonio idóneo para proyectarse a un lugar violento donde el borde se come al centro. En este sentido, la novela presenta este imaginario urbano que signa la realidad actual de las problemáticas sociales de la ciudad puerto: las calles, los bares, las formas de sobrevivir en la urbe y las fiestas en discos subterráneas se representan como una foto panorámica que expondrá a todos sus ciudadanos y las formas en que estos se relacionan. ¿Cómo ven los marginales la selva de cemento en la que se esfuerzan por sobrevivir día a día?, el protagonista nos dirá: "Yo no era nada, no 
era nadie, no tenía documentos ,nadie me conocía” (Gaete, 2015: 72). Estos seres nadie, que no son nada, van a posicionarse en la narración.

La idea de la novela es deconstruir los imaginarios de la autoridad y de poder (Rosales y Candia, 2015: 124). En este contexto, Nadie como protagonista de la novela nos muestra su habitar en la ciudad de manera directa, con lo que, a su vez, cambia la dimensión cartográfica simbólica de la urbe. A pesar de no tener un espacio físico, el protagonista proyecta su propia concepción y modo de representar la realidad en la ciudad, de esta manera, y tal como lo afirmaba Lucía Guerra, la memoria, los afectos y defectos, entre otros significados hacia la ciudad, "hacen del espacio urbano una fermentación inacabable de signos. Fermentación que oscila entre el orden y el desorden" (Guerra, 2014: 17). De esta forma, la hegemonía del imaginario es definida de acuerdo a la lectura, es decir, a la narración del personaje que habita/transita esa ciudad y esta, a su vez, permite la conexión con el imaginario urbano que viene a representar; el poder biopolítico se (re)semantiza en Valparaíso invadiendo sus espacios y apropiándose de ellos, inclusive de Valpore.

Bajo esta perspectiva, el transitar de Valparaíso a Valpore resulta un viaje en ascenso y descenso:

Trepamos a pie por los cerros del Puerto, llegando a la cúspide de la miseria desde donde se desciende a Valpore. Por un sendero en espiral que conduce a lo más bajo, pasamos frente a casas sin terminar en las que se acumulaban ladrillos y niños que apenas sabían caminar jugaban a dispararnos.

En un momento nos detuvimos, quisimos descansar, pero las piedras que nos lanzaban nos pusieron otra vez en camino hacia el plan de Valpore. La noche llegaba. La vista era la de un tornado descendente de luces; había que seguirlas para llegar al centro [...] Algunos niños nos miraban con odio, nos apuntaban con sus manitos cafés de mugre; otros sacaban relojes de sus bolsillos, para ofrecerlos; los más arriesgados trataban de meter la mano en el bolsillo del Pulpo o en el mío, pero cada vez que lo intentaban recibían una patada. Apenas sabían caminar y ya habían aprendido a robar. Era el destino en Valpore, un destino muy lejos de Valparaíso. (Gaete, 2015: 39-40)

Tal vez, para algunos la novela solo representará la violencia en su efervescencia más usual, pero va mucho más allá. Con el transcurrir de la historia, el lector entrará en la atmósfera de una novela de ciencia ficción que toca temas en la palestra de discusiones sociales actuales, ¿¿cómo y de qué manera? Pues aquí viene la reflexión que atrae gravitacionalmente a la lectura, ¿qué pasaría si todos esos punks, niños, mendigos y los marginados que dan vida a Valparaíso fueran meros clones controlados por la sombra de una fuerza superior que mantiene el poder de la ciudad en su estado actual?, ¿qué pasó con los verdaderos marginados?, ¿es necesario tener marginados sociales para que la sociedad, tal y como la conocemos, mantenga sus privilegios y diferenciaciones socioeconómicas?

En síntesis, la novela da un giro copernicano en cuanto a la forma de visualizar el imaginario de la ciudad puerto, sin duda una crítica sólida a la forma 
en que los ciudadanos "comunes" y aquellos de "más altas elites" ven las problemáticas que la ciudad puerto ha arrastrado ya durante casi un siglo:

Los mostros se apiñaron en la limosina. El chofer trató de espantarlos, retrocedió el auto e intentó hacerlo partir, pero las bocas llenas de deseo, hinchadas de pasta base, lo rodearon lentamente, se agolparon en el capó, sacaron las llantas. El chofer gritó, no podía huir, giraba el contacto infructuosamente [...] Por la ventana vi la coraza de una limusina desvalijada y un esqueleto con restos de carne y jirones de ropa apoyado sobre el manubrio. (Gaete, 2015: 16)

Esta marginalidad, fuera de las normas (Rosales y Candia, 2015: 134), fuera de la constitución de una metrópolis, cuna del progreso, arroja a una anarquía urbana descomunal, en la que los ciudadanos de Valparaíso son víctimas de un poder hegemónico mayor.

En síntesis, "nadie" escapa ante la realidad que intentamos ignorar día a día en Valparaíso, que es, a su vez, reflejo de la realidad chilena actual, donde nuestros nombres no son nada ni tenemos protección del lugar que habitamos arrojándonos a una voraz y vertiginosa forma de concebir la realidad en la que vivimos, también nosotros somos "Nadie". Valparaíso tiene así un imaginario frente a la posición anárquica, dantesca y apocalpítica (escatológica) que proyecta hacia sus habitantes, como una especie de "Mil maneras de morir"10 en Valparaíso.

\section{Cartografía de la ciudad de Valparaíso en la ciencia ficción}

Tal como se ha podido apreciar en los ejemplos anteriores, Valparaíso es concebido desde un "Plan", que, de acuerdo al sociolecto y a la concepción diatópica de su lenguaje, se entiende por el "Centro", que comenzó desde el sector de la Iglesia La Matriz y fue abarcando lo que era la Intendencia, el sector de los Bancos, etc. La marginalidad de la ciudad es evidente y va creciendo a medida que se sube por sus cerros, mientras más lejos y más arriba se llegue, más pobre y olvidado serán sus espacios, inclusive, algunos han quedado encapsulados geográficamente dado el crecimiento de la urbe; antiguos lugares como la Excárcel, los Cementerios n. ${ }^{\circ}$ 1, 2 y 3, así como otros, permiten comprender una expansión geográfica que ha arrojado a sus habitantes más marginales hacia una periferia desconocida y, como consecuencia, olvidada.

Este territorio cargado de significados presenta, a su vez, la idea binaria de construcción/destrucción que aborda la pregunta de visualizar a la ciudad de renombre en su miseria y decadencia. Como resultado, el propio origen de Valparaíso se arraiga en su esencia: desde su creación, Valparaíso es un montaje de ciudad-puerto, producto de cruces topográficos y del crecimiento de la ciudad

${ }^{10}$ Tal como aquella serie estadounidense que salió el 2008, donde se le daba un enfoque irónico a la muerte. 
sin planificación, una idea de "contracultura" (Landaeta, Rojas y Candia, 2016: 8), donde la comunidad se crea a sí misma.

Por otra parte, la ciudad se entiende como un espacio literario. En este sentido, Sergio Meier señala la idea de que la superación de la fantasía del mundo tradicional deja las antiguas nociones de ciencia ficción, en tanto que pueden ser consideradas obras literarias que, independiente de las temáticas tratadas, tienen elementos dentro de los espacios e imaginarios que permiten considerarlas obras de ciencia ficción (Lloró, 2016). En este sentido, viene a afirmar lo propuesto por Moreno (2011) y Castoriadis (2007) sobre la construcción de un Valparaíso cuyos espacios representen y simbolicen a la sociedad chilena y, en específico, a la condición socio-histórica de los habitantes de Valparaíso.

Surgen, además, las divagaciones del espacio y la metamodernidad que juegan con el tiempo pasado y futuro para la construcción del espacio, en tanto que la narración transite en torno a los espacios representados y el pensar de los sujetos que habitan en la sociedad que muestra dicho espacio literario. A su vez, cuando se trata de mapear el espacio de la ciudad y sus prospecciones no puede evitarse mencionar el hecho de que Valparaíso es un lugar de espacios cerrados. Dichos espacios permiten entender la singularidad de sus personajes y cómo estos son consumidos por un espacio mayor, la ciudad misma como un personaje que intenta sobrevivir de la plaga que la habita, consume y destruye a lo largo de los relatos.

\section{Cuando el sujeto transita y habita el espacio}

Barcelona (2006) de Néstor Flores es en particular una novela que se divide en tres partes; cada una por separado, son novelas breves e independientes que conforman en totalidad un relato macro. Para ejemplificar este apartado, en el segundo relato, "Las crías del humo", se narra la historia de jóvenes universitarios y citadinos, quienes están en búsqueda de fiestas y diversión mientras recorren los espacios nocturnos de la ciudad. Más adelante, deciden transitar hacia la periferia de la urbe. El destino era llegar a un cementerio olvidado en lo Alto de Laguna Verde, un suburbio casi olvidado de Valparaíso. En el viaje, Felipe, el conductor del grupo, se pierde y llegan a un lugar extrańo: un pequeño pueblo aparentemente inhabitado. Entran en él y la puerta de entrada se cierra tras de ellos, hasta dejarlos atrapados en total oscuridad y silencio. En discusiones sobre cómo salir y lo extraño del lugar una de las amigas de Claudia menciona: “¿A quién mierda le importa eso? —vociferó Daniela- Aquí está sucediendo algo malo, muy malo. El que haya o no ruidos es lo de menos. Lo preocupante es esa maldita puerta. Si tu no quieres dañar a alguien, entonces ¿para qué lo necesitas encerrado?” (Flores, 2006: 131).

En este contexto, el novum, vale decir, aquel extrańamiento frente a la realidad empírica que mencionaba Suvin, tiene efecto en los protagonistas. Surge así el efecto ominoso de la ciencia ficción (Cerezo, 2020), donde "la existencia de sentimientos genera en el ser humano vulnerabilidades, las cuales son importantes para experimentar alegría y sufrimiento personales y empatizar con la alegría y sufrimientos de los demás" (295). Más adelante en la narración, 
cuando logran percatarse de lo que ocurría, aparecen desde el pueblo, sus habitantes; humanoides, monstruos, bestias extrañas:

Los seres seguían aproximándose al vehículo. Venían de todas las casas del pueblo. De cada casa, salían varios de ellos; verdaderas familias de seres: altos, de estatura media, y algunos tan pequeños como un niño [...] Eran figuras de forma humana, pero diferente a los demás habitantes del planeta. No llevaban ropas, y su piel era oscura, muy oscura, de un gris ceniciento y rocoso. Algunos se arrastraban al caminar, y apenas podían levantar los pies. A simple vista, se apreciaba que no había diferenciación entre los componentes de sus rostros. Lo mismo podía ser la nariz o una negra y deforme costra lo que todos llevaban en el centro de sus semblantes. La cabeza de las crías del humo parecía ser de piedra sólida. Las orejas, los pómulos, los labios, la frente, el casco, todo no era más que irregularidades de las grises piedras que eran su cabeza. Todo era parte de aquella roca, a excepción de sus ojos, pues estos centelleaban entre la hinchazón de piedra de la frente y los pómulos como los ojos de un felino en plena noche. (Flores, 2006: 139-140)

El terror de ver a estos habitantes en los personajes es abrumador, "no solo ese sentimiento de miedo que se produce ante un ser que acaba concibiéndose como "el otro", sino que además este otro adquiere una naturaleza inquietante al ser percibido como algo que parece humano, pero no lo es" (Cerezo, 2020: 293). Entre la multitud de las criaturas del humo, se distinguía el líder de la tribu, un tipo alto vestido con “jockey Dunlop” (Flores, 2006: 142), quien lidera el ataque. Desmantelan el auto impidiendo el escape, para luego arrastrarlo hacia la tumba excavada en el cementerio. En su propio idioma, similar al español, se logra distinguir los propósitos de la criatura: “ZZdraig-gan el auzto, zdhije! ¡Zdraigganlo zaahojra al zantuahj-rio!” (160).

Tras el esfuerzo por impedir, desde el coche, la acción de las criaturas. Paulina, una de las jóvenes, logra mantener contacto con uno de los más pequeños:

— ¿Cómo te llamas?

—Flemming -contesto el niño [...]

[...]

— ¿De dónde vienen ustedes?

El muchacho levantó su dedo índice y apuntó hacia sureste, por sobre las cabezas de quienes empujaban y, accionando su tosca lengua en su boca, anunció incorrectamente:

—Zzantago. (Flores, 2006: 168)

Resulta particular este hecho, dado que la conexión de las criaturas, antes humanas, permite dilucidar su proveniencia de la capital, de la Megalópolis (Cisternas, 2011), en este caso, Santiago. Por tanto, cabe preguntarse, ¿cómo es que llegaron hasta los suburbios de otra ciudad? La respuesta la dará el pequeño ser: 
-Humo, musitó Flemming, y luego culminó—. Cáncer, piel.

$\mathrm{Y}$ en ese segundo a la nińa se le abrieron los ojos mentales y supo toda la historia del pueblo perdido; cómo se contagiaron, dónde, por qué y la razón por la cual nadie sabía la existencia de las crías del humo. (Flores, 2006: 169)

Los detalles de tal revelación no se cuentan en la historia, sino que deben ser deducidos por el lector. Las crías del humo, de alguna forma, fueron una vez seres humanos que se vieron afectados por un cambio climático de proporciones catastróficas para llegar a ese lugar apartado, marginado dentro de las marginalidades del sector de Laguna Verde en Valparaíso, lejos de la ciudad, lejos de la Polis (Cisternas, 2011), en un pequeño pueblo donde todos sus habitantes padecieron dicho cambio físico.

Por otro lado, las crías del humo realizaban una acción destacable: enterraban autos, todos aquellos que habían entrado en el pueblo, así como a sus tripulantes. Los protagonistas no fueron la excepción, puesto que los enterraron a todos. Una vez realizado este acto, el relato prosigue:

Las crías del humo empujaron el Ford. Cuando cayó, todos gritaron y entonaron cánticos triunfales. Bailaban tomados de la mano. Machos y hembras de humo se besaban felices sin distinción de sexos ni parejas. Un macho podía besar a todas las hembras del pueblo si se daba el tiempo de buscarlas, lo mismo podía hacer una hembra, y nadie le recriminaría nada a nadie. Había caído un nuevo contaminante. Todo era alegría en el pueblo esa tarde. (Flores, 2006: 181)

Este hecho, el de enterrar un contaminante, fue motivo de júbilo entre las crías del humo. Como conclusión, el Otro termina destruyendo al Yo que perturba y simboliza la propia destrucción de quienes una vez fueron los marginados de la ciudad, parte de ella y arrojados desde la Metrópolis de Santiago a algún lugar hipermarginalizado, en parte por su geografía, en parte por su simbolismo. Los no-muertos vuelven a destruir a los vivos.

El ejemplo anterior demuestra de modo fehaciente lo presentado por Elana Gomel (2017), quien realizaba el paralelismo entre esta monstruosidad del cuerpo urbano; una transfiguración figurada de la forma en que se muestran los edificios o una ciudad entera, la corporalidad de la ciudad como nexo para que se desarrollen las relaciones sociales de la ciudad, y, además, con el nacimiento de las metrópolis industriales (63), el cuerpo de la ciudad se volvió monstruoso y distorsionado, como algo que podría volverse personaje o actante de la narrativa de la misma, es decir, una característica diegética del espacio urbano en sí mismo (64). De esta forma, las ciudades se vuelven monstruos caníbales que devoran a sus propios habitantes, todo lo cual parece indicar que las ciudades de la ciencia ficción siempre suelen ser distópicas, pero esto va más allá. Gomel afirma que hay una ambivalencia mucho más profunda en el cuerpo político urbano, puesto que la misma idea de monstruosidad implica una forma de trascendencia entre lo grotesco y lo sublime (65). En síntesis, de Las crías del humo, se extrae la idea 
de que la monstruosidad de las ciudades son la expresión de deseos y miedos de un cuerpo colectivo, a saber, el de sus habitantes haciendo visibles "the spatial practices that have shaped the world we live in" (75). ${ }^{11}$

Este rol presentado, el sujeto Otro que habita el espacio y un Yo que lo transita, se invierte en la siguiente novela de la obra, al presentar una otredad arrojada a transitar por espacios de la ciudad donde el habitar lugares comunes y puntos de encuentro será una lucha constante. El tercer y último relato de la obra de Flores (2006) se denomina homónimamente como su novela macro, Barcelona, que tiene el mismo lugar geográfico dentro de la realidad y el imaginario de la ciudad de Valparaíso, donde una vez estuvo el famoso y conocido lugar de encuentro: el bar Barcelona en el Sector de Subida Ecuador. Este espacio reunía a todo tipo de gente, como por ejemplo "los raperos", "los góticos" y "los chicos anglo" (187-188). Descubre una diversidad identitaria característica de Valparaíso y sus lugares de recreación, puntos de encuentro donde se logra apreciar el intercambio cultural humano. Inmediatamente, la narración muestra la trama central de la historia: "lo mejor del Barcelona era que el DJ leía la mente de quienes estaban alrededor, y les regalaba las canciones que ellos deseaban escuchar. De alguna forma, escudriñaba el lado MTV del cerebro de todos y, cuando menos lo esperaban, ahí estaba la canción” (188).

Claudio, uno de los protagonistas de la narración, visita con su amigo, el Minga, oriundo de Chiloé, el Barcelona. En este lugar, Claudio tiene su primer encuentro con el DJ de la historia: regresando del baño, pensaba en Helter Skelter de The Beatles, cuando la canción se materializa en el bar:

—Conchetumadre - dijo Claudio dando un salto, olvidando la compañía del Minga.

— ¿Qué te pasó hueón? — preguntó exhibiendo un alto grado de preocupación.

—Esa canción. Acabo de escucharla. O sea... acabo de desear escucharla.

(...)

—No estoy hueveando. Estaba en el baño y quise escucharla. Y ahí está. El DJ la puso. El DJ la puso — repitió.

Esto último lo dijo mirando al DJ quien, para su sorpresa, tenía la mirada fija en él. El DJ le levantó la mano y le apuntó con el dedo índice. (Flores, 2006: 194)

En este deambular por el Bar, Claudio conoce mucho mejor al DJ, Ignacio, con quien forman una amistad cercana dentro de un juego de conocerse el uno al otro, que más bien es el de conocerse del Yo al Otro.

Más adelante, recorriendo la ciudad, entran en una especie de ducto que llegaba justo hacia el interior y por debajo del cementerio de disidentes de Valparaíso. En aquel lugar, Ignacio le confiesa a Claudio su propósito de estar deambulando de ciudad en ciudad:

${ }^{11}$ Traducción: "las prácticas espaciales que han dado forma al mundo en el que vivimos". 
-O sea, lo que pasa es que por lo que me dices nadie puede conocer Chile mejor que tú.

- Puede ser — dijo Ignacio con cierta melancolía.

— ¿Y por qué viajas tanto? —Consultó Claudio apurando un trago.

—Buscando [...]

—¿Qué buscai? [...]

- La verdad es que busco amistad, Claudio. Un amigo, pero un amigo de verdad.

- ¿Y no has encontrado ninguno en todo Chile? -Preguntó Claudio dejando de lado las bromas.

- Tu no cachai - dijo Ignacio como si deseara que Claudio no conociera una realidad que no le convenía observar. (205)

-Lamentablemente sé lo que piensan los hueones. Y las hueonas. Y todos quieren cagar a alguien. No necesariamente a mí. Pero siempre quieren cagar a alguien. Y no puedo evitar saber esa huevá.

— ¿Y a quién me quiero cagar yo?

—A nadie poh. Eso es lo que me sorprende. Vos soy... cómo decirlo... de verdad - lo miraba a los ojos transmitiendo la misma franqueza y bondad que había descubierto en Claudio- O sea, no tenís mala onda [...]. (Flores, 2006: 206)

Este Otro, un sujeto que transita por diversas ciudades, no logra habitarlas, dada sus capacidades, poca capacidad de asombro, es decir, de ominosidad (Cerezo, 2020) y de novum (Vargas, 2020). Esta percepción del sujeto, en su afán incontrolable por habitar la ciudad, se refleja en su transitar por los cuerpos y mentes de los sujetos que la habitan. Este será, a la larga, uno de los grandes problemas del sujeto posmoderno; su inconformidad por el espacio que habita y/o el que transita, en consecuencia, entrará en un círculo vicioso de la ciudad de Valparaíso.

\section{Hacia nuevas miradas del imaginario urbano de Valparaíso en la ciencia ficción chilena}

La ciudad es un espacio donde no solo los sujetos que la habitan transitan por ella en múltiples direcciones, tampoco se limita a una interpretación de sus rutas y espacios hegemónicos, sino más bien resulta ser un lugar donde las disciplinas del saber pueden tener puntos de encuentro y dialogar entre sí. Para el caso de la literatura, su análisis en las diversas obras que crean y representan las ciudades permiten una construcción del imaginario urbano mucho más amplia que nunca. Es precisamente en este punto que la ciencia ficción tiene un rol fundamental, sobre todo en aquellas ciudades que han sido desplazadas hacia los márgenes por el discurso imperante. Lo anterior permite entender el fenómeno de gestación de un imaginario bajo las ideas de Castoriadis (2007): no se preconcibe ni se crea, sino que se constituye (215), es decir, ya estaba en la sociedad y había que ponerlo en funcionamiento. En este sentido, las realidades se resignifican con el 
imaginario constituido, tanto a nivel personal (individuo) como a nivel de sociedad (216), por tanto, se busca pensar la sociedad mientras esta se hace a sí misma (576).

De este modo, la necesidad constante de que haya una ciudad dentro de la ciudad, es decir, imaginarios urbanos que van a formar una nueva realidad a partir del espacio físico, es primordial. A medida que pasa el tiempo, Valparaíso se degrada físicamente, pero, e inversamente proporcional a esto, se construye bajo un imaginario y prospección particularmente sólido desde la narrativa de ciencia ficción reciente.

Por otro lado, el imaginario se constituirá bajo la creación de sentidos urbanos, delimitados por los espacios externos e internos, toda vez que los personajes transiten por estos, al ser sus experiencias las determinantes al momento de conformar una simbología de los espacios. Este magma de significaciones sostiene la necesidad de que el imaginario de Valparaíso como una ciudad donde los simbolismos se sobreponen a las significaciones que denotan la urbe y, a su vez, los imaginarios constituidos connotan nuevas rutas de interpretación en la ciudad. Por este motivo, debe ser un objeto de estudio permanente la forma en que esta ciudad se transforma a través de la ciencia ficción, al dotarla de una dinámica y fuerza que permiten recorrerla bajo nuevas perspectivas. Como resultado, y ampliando lo propuesto por Childs (2015), la ciudad de Valparaíso en la ciencia ficción se considera desde la práctica cultural de este nuevo milenio, la cual se ha permeado con un repertorio de imágenes desde la percepción pública que encarna y habilita a la narrativa (99-100). Debido a esto, la ciudad será una ciudad prospectiva (Moreno, 2011), y dado que todo elemento de una ciudad prospectiva remite a la ideología de su trama, o, a su vez, hacia la intuición emocional de la narración, se trata la ciudad prospectiva en dos formas. Por un lado, la ciudad prospectiva limpia, y por otro, la ciudad prospectiva sucia, "según se pretenda manifestar la frialdad y la obsesión por el control de las personas o la degradación y decadencia de la cultura humana, representadas a través del entorno urbano" (124). Estas formas de Valparaíso están en constante lucha por interponerse en la representación de sus imaginarios.

Para concluir, el estudio de la ciencia ficción en su relación con la ciudad permitirá establecer nociones fundamentales en este siglo XXI, donde la realidad deja de ser y el sujeto se fragmenta en las urbes que parecen marginarlo, silenciarlo, violentarlo y, a la larga, engullirlo, desde el punto de vista alegórico. Más aún, conviene replantear el estudio de las literaturas regionales hacia nuevas formas disciplinarias e interdisciplinarias donde la literatura de Valparaíso aún tiene mucho que decir al respecto.

\section{BIBLIOGRAFÍA}

ARAGÓN, Milton (2014), Ciudad, simbolo e imaginario: reflexiones sobre vivir en el espacio urbano. Madrid, Liber Factory. 
Alfaro, Roy (2020), "Traducción de Una poética sociológica de la ciencia ficción de Darko Suvin", Telos: revista de Estudios Interdisciplinarios en Ciencias Sociales, vol. 22, n. ${ }^{\circ} 1$, pp. 224-234. DOI: <http://www.doi.org/10.36390/telos221>.

ARECO, Macarena (2008), "Ciudad, espacio y ciberespacio en la ciencia ficción chilena reciente: tres versiones del laberinto", Acta literaria, n. ${ }^{\circ} 37$, pp. 25-42.

ARECO, Macarena (2009), "Visión del porvenir, espejo del presente: Panorama de la ciencia ficción chilena", en Hispámerica, n. ${ }^{\circ} 38$, pp. 37-48.

ARECO, Macarena (2015), "Visión del porvenir y espejo del presente: una panorámica del casi siglo y medio de ciencia ficción chilena", en Cartografía de la novela chilena reciente: realismos, experimentalismos, hibridaciones $y$ subgéneros. Santiago, Ceibo, pp. 115-133.

ARECO, Macarena (2016), "Literatura e Historia. La ciencia ficción en Chile", Ciclo Literatura e Historia, 10 de noviembre de 2016, 19 de julio de 2018. Consultado en: <https://www.letrasdechile.cl/home/index.php/temas/ensayos/358literatura-e-historia-la-ciencia-ficcion-en-chile.html> (26/07/2020).

BARTHES, Roland (1990), La aventura semiológica. Barcelona, Paidós.

BENJAMIN, Walter (1986), El libro de los pasajes. Tiedemann, Rolf, (ed.). Buenos Aires, Akal Ediciones.

BRICEÑo, Cristián (2014), Próximo Destino y otros relatos de Xs 200. Valparaíso, Puerto de Escape.

CANDIA, Alexis; Guerra, Lucía (2018), “A cuarenta grados de Acuario. La catástrofe permanente en el imaginario urbano de Valparaíso", Anales de Literatura Chilena, n. ${ }^{\circ}$ 30, pp. 97-112.

CASTORIADIS, Cornelius (2007), La institución imaginaria de la sociedad. Buenos Aires, Tusquets.

CEREZO, Iván (2020), "Lo ominoso como categoría de la ciencia ficción", Castilla. Estudios de Literatura, vol. 11, pp. 275-300. DOI: <https://doi.org/10.24197/cel.11.2020.275-300>

Cisternas, Cristián (2011), Imagen de la ciudad en la literatura hispanoamericana y chilena contemporánea. Santiago, Editorial Universitaria.

CHILDS, Mark (2015), "Learning from new millennium science fiction cities", Journal of Urbanism: International Research on Placemaking and Urban Sustainability, vol. 8, n. ${ }^{\circ}$, pp. 97-109.

DOI: <http://dx.doi.org/10.1080/17549175.2014.891148>.

De NordenflyCHT, Adolfo (2009), "El imaginario de Valparaíso a mediados del siglo XX en Sabadomingo, novela de Juan Uribe, y en De carne y sueño, memorias de Alfredo González", Aiesthesis, n. ${ }^{\circ}$ 45, pp. 154-166.

De Nordenflycht, Adolfo (2011), "La vanguardia de Valparaíso: expresionismo de/en la periferia”, Estudios filológicos, n. ${ }^{\circ}$ 47, pp. 115-131.

FERREIRA, Rachel (2019), "Ciencia Ficción/Ficção Científica from Latin America”, en Canavan, Gerry; Link, Erik (eds.), The Cambridge History of Science Fiction. Cambridge, Cambridge University Press, pp. 664-679. DOI: $<$ https://doi.org/10.1017/9781316694374.043>.

Flores, Néstor (2006), Barcelona. Valparaíso, Puerto de Escape.

GAETE, Cristóbal (2015), Valpore. Santiago, Garceta Ediciones. 
GOMEL, Elana (2017), "Cannibal Cities: Monstrous Urban Bodies in Contemporary Fantasy", Redisco, vol. 11, n. ${ }^{\circ} 1$, pp. 62-77.

GOMEL, Elana (2018), “Divided Against Itself”: Dual Urban Chronotopes”, en Maurer, Yael; Koren-Kuik, Meyrav (eds.), Cityscapes of the future: urban spaces in science fiction. Leiden, Boston, pp. 139-150.

GUERRA, Lucía (2014), Género e imaginarios urbanos en la narrativa latinoamericana. Santiago, Cuarto Propio.

Landaeta, Patricio; Rojas, Braulio; CANDIA, Alexis (2016). "Geofilosofía de la ciudad puerto", Hybris, vol. 7, pp. 7-10.

LAWRENCE, Nick (2020), "Post-Capitalist Futures: A Report on Imagination". en Kendal, Zachary; Smith, Aisling; Champion, Giulia; Milner, Andrew (eds.), Post-Capitalist Futures: A Report on Imagination, pp. 303-327.

LINDÓN, Alicia (2007), "La ciudad y la vida urbana a través de los imaginarios urbanos", Revista eure, vol. 33, n. ${ }^{\circ} 99$, pp. 7-16.

Lloró, Carlos (2016), Conversaciones Con Sergio Meier. Valparaíso, Editorial Universidad de Valparaíso.

MARGUlis, Mario (2002), "La ciudad y sus signos", Estudios Sociológicos, vol. 20, n. ${ }^{\circ} 60$, pp. 515-536. Consultado en: <https://www.jstor.org/stable/40420719> (26/07/2020).

MeIER, Sergio (2006), "Fractales", en Valpoculto. La antología digital del terror porteño. Puerto de Escape, edición digital (CD-Rom).

Moreno, Fernando (2011), "La ciudad prospectiva", Ángulo recto. Revista de estudios sobre la ciudad como espacio plural, vol. 3, n. ${ }^{\circ}$ 2, pp. 119-131. Consultado en <http:/www.ucm.es/info/angulo/volumen/Volumen032/varia01.htm > (10/08/2020).

MuÑOZ, Martín (2014), Evento Z. Zombies En Valparaíso. Valparaíso, Forja.

NovoA, Marcelo (2006), Años Luz: Mapa Estelar De La Ciencia Ficción En Chile. Valparaíso, Puerto de Escape.

NovOA, Marcelo (2017), ";Viajeros del tiempo-espacio, embarcarse por puerta Sur?", en Letras de Chile.

Consultado en: <https://www.letrasdechile.cl/home/index.php/temas/ensayos/192viajeros-del-tiempo-espacio-embarcarse-por-puerta-sur.html> (19/07/ 2020).

Rosales, Óscar; CANDIA, Alexis (2015), "Más arriba del (Val)paraíso: desde la ciudad marginal a la ciudad demolida en Valpore", Revista de Humanidades, n. ${ }^{\circ} 32$, pp. 117-143.

SOlAR, Claudio (1964), "Valparaíso en la Literatura", Revista del Pacífico, n. ${ }^{\circ}$, pp. 99-127.

SolAR, Claudio (2001), Historia de la literatura de Valparaíso. Valparaíso, Ediciones de la Gran Fraternidad de Escritores y Artistas de la Costa.

VILLANUEVA, Marc (2018), "De la isla a la frontera. La problematización del espacio en la ficción distópica contemporánea”, Tropelías. Revista de Teoría de la Literatura y Literatura Comparada, n. ${ }^{\circ} 29$, pp. 506-521. 